RESEARCH REPORT

\title{
What underlies the high alcohol related mortality of the disadvantaged: high morbidity or poor survival?
}

\author{
P Mäkelä, I T Keskimäki, S Koskinen
}

J Epidemiol Community Health 2003;57:981-986

See end of article for authors' affiliations

\section{Correspondence to:} P Mäkelä, STAKES, PO Box 220, 00531 Helsinki, Finland; pia.makela@ stakes.fi

Accepted for publication 9 April 2003

Study objective: To investigate whether the large socioeconomic differences in alcohol related mortality can be explained by differences in morbidity or differences in survival.

Design: Register linkage study. A nationwide hospital discharge register was linked to population censuses for socioeconomic data and to the cause of death register for mortality follow up.

Setting: Finland.

Participants: Men and women aged 15 years and older discharged from hospitals with an alcohol related diagnosis in 1991-1996.

Measurements: Mortality hazard up to the end of 1997 by socioeconomic category was estimated with Cox's regression model.

Main results: Socioeconomic differences in alcohol related hospitalisation rates were almost as large as those that have been observed for alcohol related mortality. For example, the rate ratio among male unspecialised workers for any alcohol related hospitalisations was 3.6 as compared with upper white collar workers; among women the rate ratio was 2.7. Depending on gender, age, hospitalisation diagnosis, and cause of death, survival after discharge either showed no socioeconomic differences or it was worse among better off groups.

Conclusions: The study suggests that differences in survival after hospitalisation do not cause the high socioeconomic differences in alcohol related mortality.

$\mathrm{T}$ here is a strong, negative socioeconomic gradient in alcohol related mortality in many countries. ${ }^{1-3}$ This has been shown for both mortality related to long term heavy drinking and that caused by acute intoxication. The difference in Finland has been in the order of 3.5-fold to 4.5 -fold between the lowest and the highest socioeconomic group among men; among women the difference has been twofold to threefold.

Alcohol consumption habits, as reported by different socioeconomic groups in Finnish drinking habits surveys, ${ }^{45}$ offer only a partial explanation for the large socioeconomic differences in mortality: there are no systematic socioeconomic differences in the level of reported alcohol consumption, and the differences observed for the proportion of heavy drinkers, risk drinkers, and the frequency of drinking large amounts of alcohol at a time are either nonexistent or so small that they do not suffice to explain the large differences in mortality.

The reason for this discrepancy between drinking and its adverse consequences in socioeconomic groups remains a puzzle. Because alcohol related mortality is a major cause of premature death, particularly among men and in lower socioeconomic groups, and because the prevention of socioeconomic differences in mortality has a high priority, ${ }^{6}$ it would be important to find out more about the process through which people in lower socioeconomic groups end up with more alcohol related deaths even though their reported alcohol consumption is close to average.

One postulated explanation for the discrepancy is that there are socioeconomic differences in survival among people with alcohol related problems and diseases. For instance, members of lower socioeconomic groups may receive treatment of poorer quality for their alcohol related problems or alternatively they may not be able to benefit optimally from their treatment. This might apply to treatment for alcohol dependence and social alcohol problems as well as to treatment for somatic diseases.

Some previous studies have followed up a sample of clinically treated alcoholics. In the $\mathrm{UK}^{7}$ and in Sweden ${ }^{8}$ small or non-existent socioeconomic differences in mortality were found, while in Norway ${ }^{9}$ and in Canada ${ }^{10}$ a slightly higher mortality was reported for those in higher socioeconomic positions. Rossow and Amundsen showed additionally that the rate of treatment was much lower in better off groups. ${ }^{9}$ The authors concluded that heavy drinkers in higher socioeconomic positions are less likely to seek treatment for alcohol problems-that is, they have, when entering treatment, more severe alcohol problems. It is hard to know to what extent this selection effect biases the results.

In this study, we use a nationwide administrative hospital register with a follow up for mortality to examine the role of differential survival as a cause of socioeconomic differences in alcohol related mortality. These data allow us to examine socioeconomic survival differences in patients hospitalised for somatic alcohol related diseases and alcohol intoxication in addition to survival differences in patients hospitalised for alcohol dependence. It is likely that socioeconomic differences in the propensity of seeking treatment-and hence the bias in results on survival-are smaller for somatic alcohol related diseases and intoxication than for alcohol dependence.

Thus, the research questions are (1) Are there socioeconomic differences in rates of hospitalisation with alcohol related diagnoses and (2) are there socioeconomic differences in survival among those who are hospitalised with different alcohol related diagnoses.

\section{METHODS}

Data on hospital utilisation attributable to alcohol related diagnoses came from the 1991-1996 Finnish Hospital 
Table 1 Number of patients in the hospital discharge register in 1991-1996 with an alcohol related primary diagnosis, median length of hospital stay (LOS) in days, deaths during the follow up from discharge to the end of 1997, and their proportion of the patients by type of diagnosis*

\begin{tabular}{|c|c|c|c|c|c|c|}
\hline \multirow[b]{2}{*}{ Diagnosis } & \multirow{2}{*}{$\begin{array}{l}\text { Men } \\
\text { Number }\end{array}$} & \multirow{2}{*}{$\begin{array}{l}\text { Women } \\
\text { Number }\end{array}$} & \multicolumn{2}{|l|}{ All } & \multirow[b]{2}{*}{ Deaths } & \multirow[b]{2}{*}{$\%$} \\
\hline & & & Number & $\begin{array}{l}\text { Median LOS } \\
\text { (days) }\end{array}$ & & \\
\hline Alcohol psychoses & 12955 & 2571 & 15526 & 5 & 2165 & 14 \\
\hline $\begin{array}{l}\text { Alcohol dependence } \\
\text { syndrome }\end{array}$ & 19951 & 4095 & 24046 & 4 & 4001 & 17 \\
\hline Alcohol intoxication & 12833 & 3151 & 15984 & 3 & 2456 & 15 \\
\hline $\begin{array}{l}\text { Alcoholic diseases of } \\
\text { the liver }\end{array}$ & 3679 & 1169 & 4848 & 10 & 2371 & 49 \\
\hline $\begin{array}{l}\text { Alcoholic diseases of } \\
\text { the pancreas }\end{array}$ & 5951 & 1010 & 6961 & 6 & 997 & 14 \\
\hline Other alcohol related & 2390 & 366 & 2756 & 4 & 554 & 20 \\
\hline $\begin{array}{l}\text { Any alcohol related } \\
\text { diagnosis }\end{array}$ & 43132 & 9842 & 52974 & 5 & 9735 & 18 \\
\hline
\end{tabular}

*Different categories of diagnoses may include same persons, and hence their sum is larger than the total. Only first admissions in the study period are included in the table.

Discharge Register. Hospital records of the patients aged 15 and over who were discharged from any Finnish public or private hospital were individually linked to sociodemographic data in the population censuses carried out in 1990, 1985, 1980, 1975, and 1970 to obtain reliable information on socioeconomic variables. The patients who were hospitalised because of alcohol related primary diagnoses were followed up for mortality in the 1991-1997 Cause of Death Register maintained by Statistics Finland, for 3.8 years on average. The linkages were carried out using personal identity codes; the proportion of cases that could not be linked was minimal.

According to hospital type, the hospitalisations were grouped into admissions to: (1) university, (2) central, (3) district, (4) mental, (5) private, and (6) other hospitals, and (7) health centre wards. Of these hospital types, district hospitals in Finland provide specialised care in two to three main specialties, while health centre wards are mainly run by general practitioners.

In 1991-1995, the hospital diagnoses and causes of death were coded according to the Finnish version of the 9th revision of the International Classification of Diseases (ICD9), while in 1996-1997 the Finnish version of the ICD10 was used. We classified the causes of hospitalisation according to the primary diagnosis into six groups: (1) alcohol psychoses, (2) alcohol dependence syndrome, (3) alcohol intoxication, (4) alcoholic diseases of the liver, (5) alcoholic diseases of the pancreas, and (6) other alcoholic diagnoses (alcoholic gastritis, alcoholic polyneuropathy, alcoholic cardiomyopathy, alcohol dependence in pregnancy, and alcoholic beriberi disease). The term "alcohol related diseases" refers to all these groups except group 3.

Causes of death were assigned into four categories: (1) all causes, (2) causes directly attributable to alcohol-that is, deaths that have an alcohol related underlying cause (same list of causes as above for hospitalisations) - , (3) all alcohol related causes-that is, deaths that have an alcohol related underlying or contributory cause-, and (4) causes that are not alcohol related. Most common causes in category 2 were alcoholic diseases of the liver, accidental alcohol poisoning, alcoholic cardiomyopathy, alcohol dependence syndrome,

Table 2 Number of patients in the hospital discharge register in 1991-1996 with an alcohol related primary diagnosis, median length of hospital stay (LOS) in days, the ratio of alcohol related disease diagnoses to intoxication diagnoses, the number of deaths among the hospitalised during follow up from discharge to the end of 1997, and their proportion of the patients by socioeconomic status and sex

\begin{tabular}{llllll}
\hline Socioeconomic status & $\begin{array}{l}\text { Number of } \\
\text { patients }\end{array}$ & $\begin{array}{l}\text { Median LOS } \\
\text { (days) }\end{array}$ & $\begin{array}{l}\text { Alcohol related disease dg/ } \\
\text { intoxication dg }\end{array}$ & Deaths & $\%$ \\
\hline Men & & & & & \\
Upper white collar worker & 2759 & 5.0 & 3.4 & 959 & 20 \\
Lower white collar worker & 4889 & 5.0 & 3.2 & 2700 & 18 \\
Specialised manual worker & 14803 & 5.0 & 2.9 & 1949 & 19 \\
Unspecialised manual worker & 10496 & 4.0 & 2.7 & 514 & 22 \\
Farmer & 2355 & 4.0 & 2.4 & 1641 & 21 \\
Other & 7830 & 4.0 & 2.6 & 8282 & 19 \\
All & 43132 & 5.0 & 2.8 & 103 & 16 \\
Women & & & & 398 & 13 \\
Upper white collar worker & 634 & 5.5 & 2.8 & 261 & 15 \\
Lower white collar worker & 3000 & 5.0 & 2.8 & 319 & 13 \\
Specialised manual worker & 1751 & 5.0 & 2.5 & 69 & 19 \\
Unspecialised manual worker & 2388 & 5.0 & 2.5 & 303 & 18 \\
Farmer & 365 & 4.0 & 2.0 & 1453 & 15 \\
Other & 1704 & 4.0 & 2.1 & 9735 & 18 \\
All & 9842 & 5.0 & 2.5 & 2.8 & \\
All & 52974 & 5.0 & & & \\
\hline
\end{tabular}


and alcoholic diseases of the pancreas. The alcohol related contributory causes in category 3 included alcohol intoxication and alcohol related diseases. In Finland, death certificates record alcohol intoxication as a contributory cause of death more frequently and accurately than in many other countries. ${ }^{11}$

We used the socioeconomic classification of Statistics Finland. It was based on the patients' occupation in the 1990 census for the economically active and on their earlier occupation in the previous censuses for the retired and unemployed. The occupation of the head of the household was used for those with no such information available. Manual workers were divided into two on the basis of Pensola et al (http://www.valt.helsinki.fi/sosio/pru/ses.htm).

Family type was classified as follows: no family; a couple without children; a couple with children; mother or father with children; institutionalised or unknown. Language was divided into Finnish, Swedish, and other.

Hospitalisations attributable to alcohol related conditions in 1991-1996 were related to the person years of the population at risk in the 1990 census. Hospitalisation rates were adjusted for age using direct age standardisation with five year age categories and the 1990 census population as the standard.

We analysed the survival of the patients hospitalised because of alcohol related conditions by Cox's proportional hazards models (SAS Phreg). For mortality follow up, we separately identified the patients' first (index) hospitalisations in the study period 1991-1996 due to each alcohol related diagnostic category. The patient's follow up for a diagnostic category started from the end of the diagnosis specific index hospitalisation and ended at the date of the patient's death or on 31 December 1997. Hence, a person hospitalised for, for example, alcoholic liver cirrhosis at one time and for alcohol dependence at another time is included in the analyses for both of the two causes. Mortality during hospital stay was analysed separately.

\section{RESULTS}

In Finland in 1991-1996 there were nearly 53000 first hospitalisations attributable to an alcohol related primary diagnosis, $81 \%$ of which were among men (table 1). Alcohol dependence syndrome was the most common diagnosis, followed by alcoholic psychoses and alcohol intoxication. Eighteen per cent of the patients died during the follow up. Almost half of the patients hospitalised for alcoholic liver diseases died during follow up. Also the median length of hospital stay for liver cirrhosis was double the average (10 compared with 5 days).

A larger proportion of hospitalisations was due to alcohol related diseases, as opposed to intoxication, in the higher socioeconomic categories than in lower ones (table 2).

About one half of all hospitalisations with alcohol related diagnoses occurred in health centre wards. University, central, district, and mental hospitals each covered about equivalent shares of the alcohol related hospitalisations, while private hospitals only accounted for $1.7 \%$ of them.

There was a clear negative socioeconomic gradient in the rate of alcohol related hospitalisations (table 3 ). For alcohol related diagnoses in general, unspecialised manual workers had a 3.6-fold rate as compared with upper white collar workers, among men, and a 2.7 -fold rate among women. The socioeconomic differences were marked for each alcohol related diagnosis, but they were smaller than average especially for alcoholic diseases of the liver, alcoholic diseases of the pancreas, and, among women, alcohol psychoses.

In analysing the survival of the discharged patients, we divided the patients into three groups on the basis of their main diagnosis: (1) alcoholic diseases of liver or pancreas, (2) alcohol dependence, alcohol psychoses and "other", and (3) intoxication. Among both genders, there were no statistically significant differences in survival between socioeconomic groups in any of these diagnosis groups (table 4). The data were further divided into three age categories (15-44, 45-59, $60+$ ). In the second hospitalisation category (alcohol dependence, etc), there was a statistically significant interaction between age group and socioeconomic status among men $(p=0.024)$ : in the youngest age group the male upper white collar workers had an increased mortality rate, while in the oldest age group the gradient was in the opposite direction.

No direct measure of the severity of disease was available in the hospital records. As proxies in the models shown in table 4 we used the cause for hospitalisation, hospital type (cause specific survival was worse than average in university hospitals and district hospitals and better than average in private hospitals), and the length of hospital stay (the longer the stay, the worse the survival). The treatment of upper socioeconomic groups was longer than average in duration and took place more often than average in university and private hospitals. This suggests that, besides the severity of disease, the inclusion of length of stay and hospital type into the model may control for quality of treatment, which we would not like to control for, because it is a potential mediating factor between socioeconomic status and mortality. Therefore, the models in table 4 were refitted without these two variables. The results were almost identical with those in table 4.

Two further sets of models were run to check the validity of the results in table 4. Firstly, in the follow up shown in table 4, large differences between the socioeconomic groups may exist in health status at the beginning of the study period in 1991 and in the number of alcohol related hospitalisations before the beginning of the period. To make sure that these factors do not confound the results, all those who were hospitalised with an alcohol related diagnosis in 1991 or 1992 were excluded from the analysis. This did not substantially modify the results (for example, rate ratios among male unspecialised manual workers were 1.19, 1.05, and 0.97).

Secondly, the follow up in table 4 started from the moment when the patient was discharged from hospital. Analysis of mortality during the hospitalisation period was only possible among men because of the small numbers among women. The results were not substantially different from those in table 4: there were no statistically significant differences between socioeconomic groups.

Table 5 shows cause specific survival by type of hospital diagnosis. In the first cause of death category the underlying cause is directly attributable to alcohol, while the second includes additionally those deaths where a contributory cause is alcohol related. The third category consists of deaths not related to alcohol. For all three cause of death categories, there were few statistically significant differences between the socioeconomic groups. When the hospitalisation diagnosis was alcohol dependence or alcohol psychosis, among women it was the upper white collar workers who had an increased risk to die from alcohol related causes.

\section{DISCUSSION}

We set out to examine whether the high socioeconomic differences in alcohol related mortality observed in previous studies could be attributed to either differences in rates of hospitalisation or differences in survival during or after hospitalisation. Our follow up ranged from one to seven years, averaging 3.8 years. Hence, our study design excluded alcohol related deaths that occurred either after a long time after 
Table 3 Rate ratios of index hospitalisations (age adjusted) by socioeconomic status (SES), type of diagnosis, and sex. Rate ratios with $95 \%$ confidence intervals that do not include 1.0 are marked in bold

\begin{tabular}{|c|c|c|c|c|c|c|c|}
\hline SES & Diagnosis & & & & & & \\
\hline Men & $\begin{array}{l}\text { Alcohol } \\
\text { psychoses }\end{array}$ & $\begin{array}{l}\text { Alcohol dependence } \\
\text { syndrome }\end{array}$ & $\begin{array}{l}\text { Alcoholic } \\
\text { intoxication }\end{array}$ & $\begin{array}{l}\text { Alcoholic diseases } \\
\text { of the liver }\end{array}$ & $\begin{array}{l}\text { Alcohol diseases } \\
\text { of pancreas }\end{array}$ & $\begin{array}{l}\text { Other alcohol } \\
\text { related }\end{array}$ & $\begin{array}{l}\text { Any alcohol } \\
\text { related }\end{array}$ \\
\hline Upper white collar & 1.0 & 1.0 & 1.0 & 1.0 & 1.0 & 1.0 & 1.0 \\
\hline Lower white collar & 1.6 & 1.6 & 1.5 & 1.2 & 1.6 & 1.6 & 1.5 \\
\hline Specialised manual & 2.9 & 3.0 & 2.8 & 1.6 & 2.5 & 3.4 & 2.7 \\
\hline Unspecialised manual & 3.7 & 4.1 & 3.9 & 1.8 & 2.7 & 4.3 & 3.6 \\
\hline Farmer & 1.6 & 1.8 & 1.9 & 0.9 & 1.0 & 1.6 & 1.6 \\
\hline Other & 3.1 & 3.5 & 3.1 & 1.7 & 2.1 & 3.7 & 3.0 \\
\hline Women & & & & & & & \\
\hline Upper white collar & 1.0 & 1.0 & 1.0 & 1.0 & 1.0 & 1.0 & 1.0 \\
\hline Lower white collar & 1.1 & 1.3 & 1.2 & 1.2 & 1.1 & 1.8 & 1.2 \\
\hline Specialised manual & 2.2 & 2.7 & 2.7 & 1.9 & 2.4 & 4.1 & 2.5 \\
\hline Unspecialised manual & 2.3 & 3.1 & 3.1 & 1.7 & 2.2 & 3.9 & 2.7 \\
\hline Farmer & 0.9 & 1.2 & 1.6 & 0.7 & 0.4 & 0.8 & 1.1 \\
\hline Other & 1.8 & 2.7 & 2.5 & 2.1 & 1.5 & 4.0 & 2.3 \\
\hline
\end{tabular}

hospitalisation or without any hospitalisation. In principle it is possible that the results would be different with a longer follow up, but we see no evident reasons for this.

We found large socioeconomic differences in rates of alcohol related hospitalisations for all alcohol related diagnosis groups, although less so for alcoholic liver diseases. In contrast, there were practically no differences in survival after hospitalisation for alcoholic diseases of liver or pancreas or for intoxication. After hospitalisation for alcohol dependence or alcohol psychosis, young men's mortality from all causes and women's mortality from alcohol related causes was highest in upper white collar workers.

The finding of the non-existent or even reversed socioeconomic differences in survival after hospitalisation due to alcohol related conditions is in contrast with results obtained for other causes: a negative socioeconomic gradient is observed in survival for several diseases in Finland and elsewhere. ${ }^{12-15}$

The results on the reversed socioeconomic gradient among women for alcohol related deaths and among young men for deaths from all causes after hospitalisation for alcohol dependence and alcohol psychoses are similar to the findings previously reported on the overall survival of alcoholics in treatment. ${ }^{910}$ It is not plausible that the quality of treatment would explain this difference. Rather, it is probable that, even if we tried to control for the severity of disease by controlling for the length of hospital stay, type of diagnosis, and type of hospital, and used a wash out period of two years, members of higher socioeconomic groups obtain the diagnosis of alcohol dependence/alcohol psychosis in more severe cases than members of lower socioeconomic groups.

One potential reason for the differences in the severity of disease could be that in higher socioeconomic groups people try to avoid and postpone the hospitalisation for an alcohol related condition more than in lower socioeconomic groups. This would be more easily done in the case of alcohol dependence than in the case of, for example, liver cirrhosis. Alternatively, doctors could be less prone to give the diagnosis of alcohol dependence/alcohol psychosis to members of upper socioeconomic groups except in severe cases. The diagnoses of alcoholic diseases of liver and pancreas may be less dependent on medical discretion, which would explain why a reversed socioeconomic gradient was not observed for them.

Table 4 Hazard ratios for all cause mortality among patients discharged from a hospital for an alcohol related diagnosis, by type of diagnosis and socioeconomic group*

\begin{tabular}{|c|c|c|c|c|c|c|}
\hline \multirow[b]{2}{*}{ SES } & \multicolumn{6}{|c|}{ Discharge diagnosis } \\
\hline & \multicolumn{2}{|c|}{$\begin{array}{l}\text { Alcoholic disease of liver } \\
\text { or pancreas }\end{array}$} & \multicolumn{2}{|c|}{$\begin{array}{l}\text { Alcohol dependence or } \\
\text { alcohol psychoses }\end{array}$} & \multicolumn{2}{|c|}{ Intoxication } \\
\hline Number of deaths & 2738 & & 5917 & & 2111 & \\
\hline Upper white collar & 1.00 & & 1.00 & & 1.00 & \\
\hline Lower white collar & 1.09 & (0.93 to 1.28$)$ & 0.98 & (0.86 to 1.12$)$ & 1.00 & (0.80 tol.26) \\
\hline Specialised manual & 1.09 & (0.94 to 1.26 ) & 0.96 & (0.85 to 1.08 ) & 0.97 & (0.80 to 1.18$)$ \\
\hline Unspecialised manual & 1.09 & (0.93 to 1.27$)$ & 1.00 & (0.89 to 1.13$)$ & 1.00 & (0.82 to 1.22$)$ \\
\hline Farmer & 1.21 & (0.99 to 1.48 ) & 0.95 & $(0.82$ to 1.10$)$ & 0.90 & $(0.70$ to 1.15$)$ \\
\hline Other & 1.19 & (1.01 to 1.39 ) & 1.03 & $(0.91$ to 1.16$)$ & 0.98 & (0.80 to 1.21 ) \\
\hline $\begin{array}{l}\text { ( } p \text { for trend when }<0.1) \dagger \\
\text { Women }\end{array}$ & & - & & - & & - \\
\hline Number of deaths & 630 & & 803 & & 345 & \\
\hline Upper white collar & 1.00 & & 1.00 & & 1.00 & \\
\hline Lower white collar & 0.97 & (0.71 to 1.33 ) & 0.82 & (0.62 to 1.09 ) & 1.14 & $(0.70$ to 1.88$)$ \\
\hline Specialised manual & 0.90 & (0.64 to 1.27$)$ & 0.95 & (0.71 to 1.28 ) & 1.57 & (0.95 to 2.60$)$ \\
\hline Unspecialised manual & 0.95 & (0.68 to 1.33 ) & 0.76 & (0.56 to 1.01$)$ & 1.07 & (0.64 to 1.77$)$ \\
\hline Farmer & 1.27 & (0.80 to 2.02$)$ & 1.03 & (0.68 to 1.56$)$ & 1.24 & $(0.63$ to 2.45$)$ \\
\hline Other & 1.16 & (0.83 to 1.63$)$ & 0.99 & (0.74 to 1.33 ) & 1.41 & (0.85 to 2.34 ) \\
\hline ( $p$ for trend when $<0.1$ ) $\dagger$ & & - & & - & & - \\
\hline
\end{tabular}




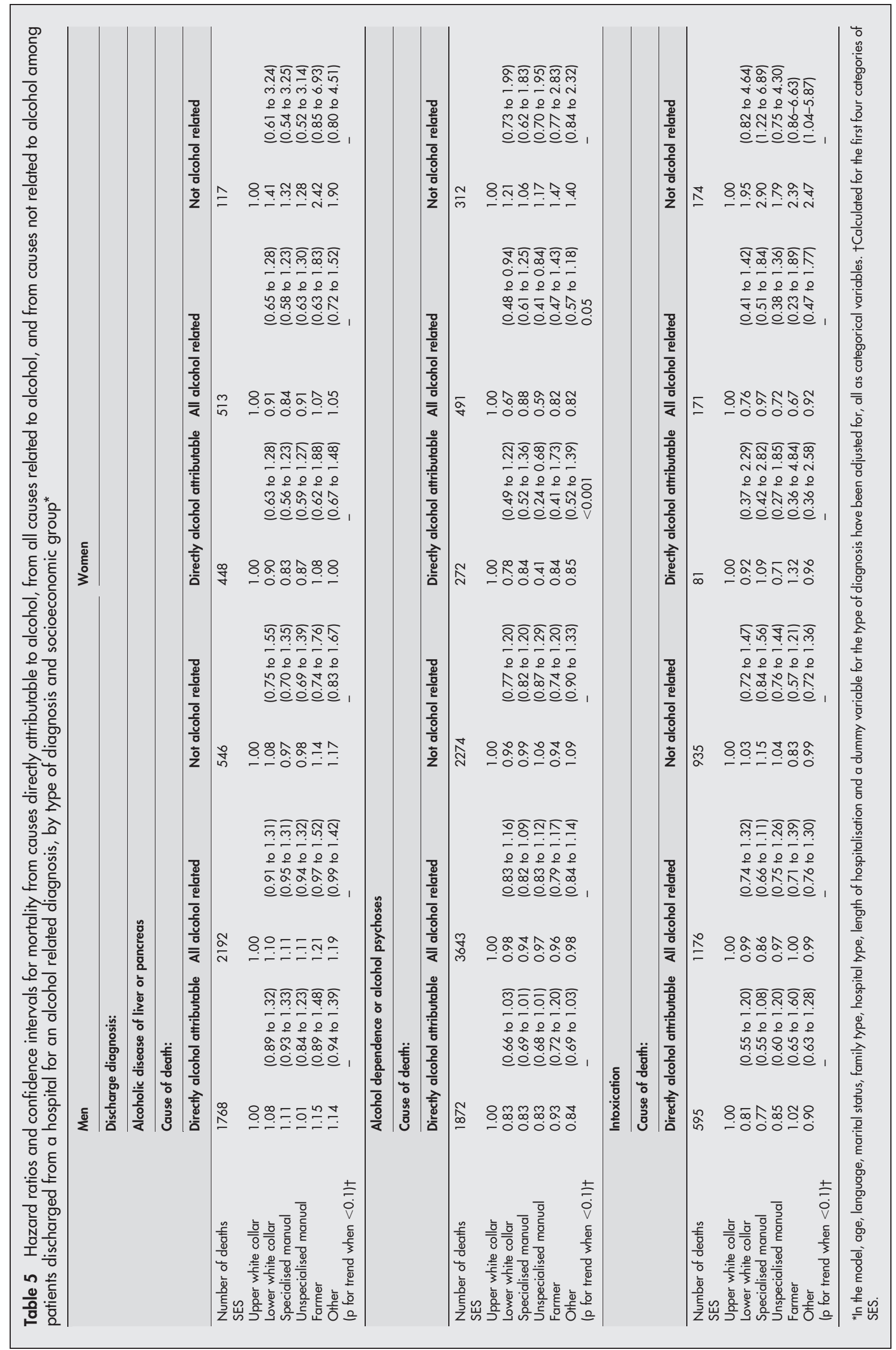




\section{Key points}

- Eighteen per cent of all patients hospitalised because of an alcohol related diagnosis, and almost half of those hospitalised for alcoholic liver diseases, died during the average follow up of 3.8 years.

- A socioeconomic gradient existed for the incidence of hospitalisations attributable to each alcohol related diagnosis group, but it was less marked for alcoholic liver disease.

- Hospitalisations because of alcohol related diagnoses, and because of intoxication in particular, were much less frequent in white collar workers than in other socioeconomic groups.

- There were no systematic statistically significant differences in all cause mortality between socioeconomic groups after or during hospitalisations attributable to alcohol related somatic diseases or intoxication.

- Upper white collar workers hospitalised because of alcohol dependence or psychosis had, among women, an increased risk to die from alcohol related causes and, among young men, from all causes.

In conclusion, the strong socioeconomic gradient in mortality from alcohol related causes in Finland cannot be attributed to socioeconomic differentials in the quality of hospital treatment or other factors operating through survival after hospitalisation. The reasons for the mortality differences have to be located causally earlier, in higher incidence of alcohol related health problems in the lower socioeconomic groups. Hence, further preventive measures should be targeted to drinking habits and to early prevention of alcohol problems. This conclusion is in contrast with the results of surveys on drinking habits, ${ }^{45}$ which do not show significant variation in alcohol consumption by socioeconomic position. It is possible that surveys on drinking habits provide a distorted picture of socioeconomic variations in alcohol consumption, due to socioeconomic differences in alcohol consumption among the non-respondents and in the accuracy of reported alcohol consumption among the respondents. Moreover, it is possible that other environmental or behavioural factors augment the harmful effects of alcohol in lower socioeconomic groups. ${ }^{1}$

\section{ACKNOWLEDGEMENTS}

The authors wish to thank Marjo Jansson and Sonja Lumme for conducting the statistical analyses.

\section{Policy implications}

- The study underlines the importance of early prevention of alcohol problems as a preventive measure to reduce high socioeconomic inequalities in alcohol related mortality.

\section{Authors' affiliations}

P Mäkelä, I Keskimäki, STAKES, National Research and Development Centre for Welfare and Health, Finland

S Koskinen, KTL, National Public Health Institute, Finland

\section{REFERENCES}

1 Mäkelä P. Alcohol-related mortality as a function of socioeconomic status. Addiction 1999:94:867-86.

2 Romelsjö A, Lundberg $M$. The changes in the social class distribution of moderate and high alcohol consumption and of alcohol-related disabilities over time in Stockholm County and in Sweden. Addiction 1996:91:1307-23.

3 Harrison L, Gardner E. Do the rich really die young? Alcohol-related mortality and social class in Great Britain, 1988-94. Addiction 1999;94:1871-80.

4 Metso L, Mustonen H, Mäkelä P, et al. Suomalaisten juomatavat vuonna 2000. Taulukkoraportti vuoden 2000 tutkimuksen perustuloksista ja vertailuja aiempiin juomatapatutkimuksiin. [Finnish drinking patterns in 2000. Basic tables from year 2000 survey and comparisons to earlier surveys]. Helsinki: Stakes, 2002.

5 Mäkelä P, Holmila M, Kaukonen O. Päihteet ja päihdepolitiikka [Alcohol, drugs and alcohol and drug policy]. In: Kangas I, Keskimäki I, Koskinen S, et al, eds. Kohti Terveyden Tasa-arvoa [Towards health equality]. Helsinki: Edita, 2002:101-22.

6 WHO. Regional Office for Europe. Health 21 - health for all in the 21 st century. An Introduction. Copenhagen: European Health for All Series no 5, WHO, 1998

7 Edwards G, Kyle E, Nicholls P, et al. Alcoholism and correlates of mortality. Implications to epidemiology. J Stud Alcohol 1978;9:1607-17.

8 Lindberg S, Ågren G. Mortality among male and female hospitalized alcoholics in Stockholm 1962-1983. British Journal of Addiction 1988;83:1193-200.

9 Rossow I, Amundsen A. The disadvantage of being advantaged? On a social gradient in excess mortality among alcohol abusers. Addiction 1996;91:1821-9

10 Schmidt W, DeLint J. Social class and the mortality of clinically treated alcoholics. British Journal of Addiction 1970:64:327-31.

11 Mäkelä P, Valkonen T, Martelin T. Contribution of deaths related to alcohol use to socioeconomic variation in mortality: register based follow up study. BMJ 1997:315:211-16.

12 Forssas E, Keskimäki I, Reunanen A, et al. Widening socioeconomic mortality disparity among diabetic people in Finland. Eur J Public Health 2003;13:38-43.

13 Kogevinas M, Porta M. Socioeconomic differences in cancer survival: a review of the evidence. IARC Sci Publ 1997;138:177-206.

14 Kunst AE, Groenhof F, Mackenbach JP, and the EU Working Group on Socioeconomic Inequalities in Health. Óccupational class and cause specific mortality in middle aged men in 11 European countries: comparison of population based studies. BMJ 1998;316:1636-42.

15 Salomaa V, Niemela M, Miettinen H, et al. Relationship of socioeconomic status to the incidence and prehospital, 28-day, and 1-year mortality rates of acute coronary events in the FINMONICA myocardial infarction register study. Circulation 2000;101:1913-18. 